\title{
Correction to: Commentary to: TDOA versus ATDOA for wide area multilateration system
}

\author{
Daniel Frisch $^{*}$ and Uwe D. Hanebeck
}

\author{
The original article can be found \\ online at https://doi.org/10.1186/ \\ s13638-020-1656-1. \\ * Correspondence: daniel.frisch@ \\ ieee.org \\ Chair for Intelligent \\ Sensor-Actuator-Systems (ISAS), \\ Karlsruhe Institute of Technology \\ (KIT), Adenauerring 2, D-76131 \\ Karlsruhe, Germany
}

\section{Correction to: EURASIP J. Wireless Com. Network. 2020, 43 (2020) https://doi.org/10.1186/s13638-020-1656-1}

Following publication of the original article [1], two concerns were brought to the attention of EURASIP Journal on Wireless Communications and Networking.

Firstly, an incorrect naming convention has been used for the article title; the article had been titled Correction to: TDOA versus ATDOA for wide area multilateration system, while it should be titled Commentary to: TDOA versus ATDOA for wide area multilateration system.

Please find now the correct title in the original article and in this correction.

Secondly, a number of the mathematical equations in the article had been published with minor formatting errors, mainly concerning (incorrect) differences between the formatting of the equations in the article PDF versus the online version of the article.

The formatting has been corrected in the original article. Please note that the significance of the equations is not affected by this correction to the formatting.

The publisher apologizes for these technical processing errors.

Published online: 25 May 2020

\section{Reference}

1. Frisch, Hanebeck, Commentary to: TDOA versus ATDOA for wide area multilateration system. EURASIP J. Wireless Com. Network. 2020, 43 (2020). https://doi.org/10.1186/s13638-020-1656-1 (c) The Author(s). 2020 Open Access This article is licensed under a Creative Commons Attribution 4.0 International License, which permits use, sharing, adaptation, distribution and reproduction in any medium or format, as long as you give appropriate credit to the original author(s) and the source, provide a link to the Creative Commons licence, and indicate if changes were made. The images or other third party material in this article are included in the article's Creative Commons licence, unless indicated otherwise in a credit line to the material. If material is not included in the article's Creative Commons licence and your intended use is not permitted by statutory regulation or exceeds the permitted use, you will need to obtain permission directly from the copyright holder. To view a copy of this licence, visit http://creativecommons.org/licenses/by/4.0/. 